\title{
QUEEN'S
QNEIVERSITY
BELFAST
}

\section{A novel approach for understanding trauma related youth violence in low resource contexts: A retrospective case file review in Northern}

Ireland

Walsh, C., Best, P., \& Doherty, K. (2021). A novel approach for understanding trauma related youth violence in low resource contexts: A retrospective case file review in Northern Ireland. Violence: An International Journal . https://doi.org/10.1177/2633002421991841

Published in:

Violence: An International Journal

Document Version:

Publisher's PDF, also known as Version of record

Queen's University Belfast - Research Portal:

Link to publication record in Queen's University Belfast Research Portal

\section{Publisher rights}

Copyright 2021 the authors.

This is an open access Creative Commons Attribution-NonCommercial License (https://creativecommons.org/licenses/by-nc/4.0/), which permits use, distribution and reproduction for non-commercial purposes, provided the author and source are cited.

\section{General rights}

Copyright for the publications made accessible via the Queen's University Belfast Research Portal is retained by the author(s) and / or other copyright owners and it is a condition of accessing these publications that users recognise and abide by the legal requirements associated with these rights.

\section{Take down policy}

The Research Portal is Queen's institutional repository that provides access to Queen's research output. Every effort has been made to ensure that content in the Research Portal does not infringe any person's rights, or applicable UK laws. If you discover content in the

Research Portal that you believe breaches copyright or violates any law, please contact openaccess@qub.ac.uk. 


\title{
A novel approach for understanding trauma-related youth violence in low resource contexts: A retrospective case file review in Northern Ireland
}

Violence: An international journal

(C) The Author(s) 2021

(c) (i) (\$)

Article reuse guidelines: sagepub.com/journals-permissions DOI: I0.1 I77/263300242199/84| journals.sagepub.com/home/vio

@SAGE

\section{Colm Walsh iD}

Queen's University Belfast, UK

\section{Kelvin Doherty}

Youth Justice Agency of Northern Ireland, UK

\section{Paul Best}

Queen's University Belfast, UK

\begin{abstract}
Adverse life events during childhood have been associated with increased rates of violence. Despite decades of violent conflict, there continues to be a paucity of contextually relevant data related to youth violence in Northern Ireland. Prospective studies are useful but these require time and resources that are not often available. In the absence of such studies, there remains a need to understand the prevalence and impact of serious youth violence in a cost-effective and timely way. The primary aim of this study is to present a novel method for collecting and analyzing violencerelated data using existing administrative data through a retrospective case file review of young people aged I0-18 who spent time in custodial services $(n=145)$ over a I-year period (January 2019 to December 2019) in Northern Ireland. A digital worksheet was developed and following a review, data from each file were extracted. Analyses examined the relationship between potentially traumatic life events and violent offending. Consistent with previous studies, this study found that rates of both adversity and violent offending are high. However, not all forms of adversity are associated with the same violent outcomes. Regression models illustrated, for instance, a significant
\end{abstract}

\footnotetext{
Corresponding author:

Colm Walsh, SSESW, Queen's University Belfast, 7 College Park, Belfast BT7 INN, UK.

Email: colm.walsh@qub.ac.uk
} 
relationship between community-based victimization and violent offending. Those who experienced more serious forms of violence were more likely to engage in higher harm violence. This study adds to the international literature on psychological trauma and youth violence and makes recommendations for future investigation.

\section{Keywords}

adversity, data, Northern Ireland, trauma, youth violence

\section{Introduction}

Since the late 1990s, there has been an explosion in interest around the impact of adversity on children and young people both in the short term and over the longer term. This has been facilitated in part by advances in analytical techniques, technological feats, and increased investment. Adverse Childhood Experiences or "ACEs" popularized by Vincent Felitti et al.'s (1998) seminal report has become synonymous with traumarelated research. The studies undertaken by Felitti and colleagues illustrated that exposure to adversity during childhood is significantly associated with a range of psychological, biological, and behavioral outcomes through childhood and even into adulthood. Subsequent large studies have also shown that these traumatic responses to adversity are alarmingly high in childhood (Levenon and Grady, 2016), and have consistently demonstrated that exposure to potentially traumatic experiences during the formative years of adolescence are associated with a range of deleterious outcomes across the life course (Abate et al., 2017; Bellis et al., 2014; Blum et al., 2019). Outcomes include escalated incidents of aggression and violence.

Sociological and criminological work has consistently found that youth engaged within the justice system are themselves often exposed to another form of adversity: interpersonal community-based violence. Interpersonal violence is a highly prevalent form of adversity that appears to be elevated in areas of high community tension and conflict. Interpersonal adversities, and in particular violent ones, appear to be more consistently related to subsequent violence offending (Baglivio et al., 2021). As they have been mooted since the late 1980s, decades of evidence have observed the criminogenic effects of childhood violent victimization, often referred to as the "victim-offender overlap" or the cycle of violence (Widom, 1989). But the relationship is by no means clear. While victims of interpersonal trauma are at increased risk of perpetrating violence, so that violent adversities will go on to perpetrate violence themselves (Wright et al., 2019), it is also true that not everyone experienced adversity as a child.

Understanding the relationship between adversity and violence can be important for identifying those most at risk, and by extension, potential opportunities to design and test prevention approaches. International standards for the protection of children against violence and its related harms are enshrined in the United Nations Convention on the Rights of the Child (UNCRC) and yet, the vast majority of interpersonal violence goes under recorded. This makes analysis of adversity, including community-based violence, critical to advancing the prevention of violence itself. This article presents a novel approach to collecting data in a cost-effective way, which is informed by existing administrative and 
empirical data, as well as useful theoretical approaches that help to construct reasonable explanations for the presence (or absence) of interpersonal violence.

\section{Violence-related data}

Figures from global bodies such as the World Health Organization (WHO) illustrate the long arm of violence. The burden appears profound. Globally, it is estimated that one out of two children aged 2-17 years suffer some form of violence each year, and one-third of adolescents are victimized by peer-related violence (WHO, 2020). The collection and analysis of disaggregated administrative data combined with investment in high-quality empirical studies have been an important step in identifying those in need of support. However, administrative data are often limited, aggregated, and difficult to elucidate the impact of distinct forms of adversity on particular populations, thereby reducing the association between these and specific behavioral outcomes. The most widely available and reliable data sources include official justice figures and mortality rates published by health departments (Prinsloo et al., 2015), but the majority of violence relates to nonfatal injuries and very often victims' injuries remain unreported.

High-quality and often prospective studies have provided additional insights and helped to address some of the gaps with administrative data. Some of these have estimated that up to $60 \%$ of young people are exposed to violence (Farrell and Zimmerman, 2017). However, they also suggest that this is experienced disproportionally by particular communities and populations. In one study, Catherine Shaffer et al. (2019) found that internalizing symptoms (such as over-inhibited or internally focused symptoms including anxiety, fear, sadness/depression, social withdrawal, and somatic complaints) increased the risk of frequent and more serious forms of perpetration of violence in areas of high disadvantage but not of low disadvantage. Another study estimated that although only $12 \%$ of reported violence is committed by young people, there is a sub group of less than $10 \%$ of young people who are responsible for more than half of all serious youth violence (Piquero, 2011).

Later studies have sought to unpack these findings to understand the nuances within these observations. In a prospective longitudinal birth cohort, James Topitzes et al. (2012) found that, by controlling for the same types of adversity, males were significantly more likely to engage in violent offending. Furthermore, although family functioning and educational stability were important, it was only for males that it predicted increased rates of violence. This appears to illustrate some gender differentiation in how youth respond to traumatic experiences, with boys more likely to present with externalizing difficulties, or a spectrum of disinhibited or externally focused behavioral symptoms including aggression, conduct problems, delinquent behavior, oppositionality, hyperactivity, and attention problems.

In fact, this observation has been one of the most frequently repeated observations (Maschi and Bradley, 2008). In their study, Bryanna Fox et al. (2015) explored the odds of engaging in serious and chronic violence. Although dose-response effect of adversity was a significant predictor, the strongest predictor was gender, with the odds of young men engaging in serious violence four times greater than young women $(O R=4.69)$. 
The contribution made by some international studies that have used administrative and/or prospective empirical data have been immense. And yet, some of these same studies have suggested nuances within the data. Therefore, combining what is known broadly regarding risk and protective factors with contextually and culturally relevant data, for example, in places such as Northern Ireland (NI), could enhance prevention efforts. Indeed, Colin Knox (2002) notes that NI is synonymous with the word "violence."

Between 1969 and 1998, the period known as "the Troubles," the population of NI was directly and vicariously affected by the murder of more than 3,700 people, compounded with the injury of 40,000 more (McKittrick et al., 2007). In analyses of the conflict and its legacy, it is regularly reported that young men accounted for a high proportion of Troubles-related-deaths (e.g. Smyth et al., 2004), and disproportionally experienced paramilitary violence (Fay et al., 1998). Throughout the Troubles, young men were also those more likely to be perpetrators of conflict-related violence. A more recent prevalence study of youth mental health undertaken by Lisa Bunting et al. (2020) found that the most commonly reported traumatic events for young people below 18 years in NI was violence related. Although several studies have sought to investigate young people's relationship with violence in post-conflict NI (see, for example, Walsh and Schubotz, 2020; YANI, 2001), these have tended to rely on qualitative data with few studies examining young people's exposure to violence (both as victim and perpetrator) and how adversity within this context affects behavioral outcomes such as violence.

Understanding the ways in which young people in NI continue to be exposed to violence and other forms of adversity that are predictive of violent perpetration are important for the development of effective prevention strategies but also critical for the transition towards peace. Recent data appear to illustrate the persistent threat of violence within some communities across NI. Despite more than two decades since the upsurge of optimism that came with the peace accord in 1998, young people continue to report concerns around their personal safety (Walsh, 2020a), experience peer-related community violence, paramilitary threat and coercion, and paramilitary exploitation (EANI, 2020).

\section{Theoretical considerations}

In trying to understand the elevated prevalence of peer and organized violence in some NI communities, the concept of intergenerational trauma has significant utility. Intergenerational trauma describes a phenomenon whereby those who do not directly experience traumatic events nevertheless present increased psychological distress. This has been observed in populations that have experienced significant collective trauma, such as Holocaust survivors and their children who were not directly exposed to the traumatic events (Fonagy, 1999) or the children of those who were present during the 9/11 attacks (Yehuda et al., 2005). Although the behavioral and psychological mechanisms are not clear, observations from NI have found deleterious psycho-social effects among second generation of those directly affected by conflict-related violence. It is evident that the Irish Troubles have left a legacy and social issues that have permeated throughout Northern Irish society (Kapur and Campbell, 2004) with particular enduring effects for younger people (McAlister et al., 2011). For example, researchers have found stress symptoms among the children of those who witnessed the killing of 13 civilians 
during a civil rights demonstration in the city of Derry, NI in 1972 (McGuigan and Shevlin, 2010). This "trans-generational effect" has also been described by others (Goodman and West-Olatunji, 2008; Van der Kolk et al., 1996). Natan Kellermann (2001) distinguished four different theoretical models for how this transmission takes place: psychodynamic and relational, sociocultural, family systems and communication, and biological models of transmission. Psychodynamic models have claimed that the child unconsciously absorbs the repressed experiences of the survivor parent (e.g. Volkan, 1996). Sociocultural models highlight the primacy of family systems and parenting practices. Parenting styles are highly predictive of both pro and antisocial behavioral outcomes (see Henggeler et al., 1998), however, when parents themselves have been traumatized, the psycho-social outcomes for their children can be affected no matter the education they receive (Schwerdtfeger et al., 2013). Biological or genetic models of transmission have proposed that traumatization can be passed on through a genetic or biochemical predisposition (Fargas-Malet and Dillenburger, 2016). Ronald Kessler et al. (1995) suggest a lifetime prevalence for Post-Traumatic Stress Disorder (PTSD) of 8\% with the risk of it developing following a traumatic incident recorded at $23.6 \%$ (Breslau et al., 1991, 1997). Meta-analyses suggest common risk factors for PTSD severity include a lack of social support and additional life stress (e.g. Brewin et al., 2000). Given the historical context within NI, some studies estimate that as much as 1 in 20 people in NI has clinical levels of PTSD (Ferry et al., 2014).

The fifth edition of the Diagnostic and Statistical Manual of Mental Disorders, the DSM-5 (Weathers et al., 2013), outlines eight key criteria for PTSD diagnosis. This includes (a) exposure to actual or threatened death, serious injury or sexual violence; (b) intrusion symptoms; (c) persistent avoidance; (d) negative alterations in cognitions and mood; (e) marked alterations in arousal and reactivity; (f) duration longer than 1 month; (g) significant distress or impairment in functioning; and (h) not attributable to effects of a substance or a medical condition (Weathers et al., 2013). However, the purpose of this study was not to clinically diagnose PTSD using case file data but rather to examine potential indicators of trauma through the records of potentially traumatic life events.

Well-established theories provide some additional insights. General theories of crime such as the strain theory (Agnew, 1992) and the social learning theory (Bandura, 1979) have enabled rigorous testing of hypothesis that link victimization to perpetration. Combined, these approaches to violence situate violent behavior within an ecology of interconnected systems, each susceptible to changes in the other. Adaptations of the social learning theory suggest that young people may behave violently when they observe aggression such as in the home or when they live in communities that experience high levels of conflict. In the presence of childhood adversity such as violent victimization, the general strain theory (Agnew, 1992) suggests that overwhelming emotions can result in aggressive and violent behavior, the aim of which is to address what is perceived to be unjust. The observations suggest that young men are under particular pressure to respond to one particular form of strain (disrespectful treatment) with limited resources with which to respond (Agnew, 2001; Anderson, 1999). Subcultural norms can legitimize violence, through feelings of injustice and the perception that their status will be enhanced, thereby reducing the risk of further disrespectful treatment by providing a coping strategy which is both effective and perceived as feasible (Agnew, 2001). 
In many ways, the overlap between victim and perpetrators is most pronounced among the justice-involved population (Jennings et al., 2012; Kar, 2019) and from a theoretical perspective, this group of young people are relatively more likely to have experienced chronic social strains and higher trauma load, and are less likely to have positive and consistent social supports and, finally, are more likely to be disproportionately from economically and socially disadvantaged communities.

\section{Associations between trauma and violence}

Using international data, it has been estimated that up to $90 \%$ of those involved in the youth justice system self-report some previous adverse events during childhood. On average, they have experienced 4.9 types of adversity $(S D=2.9)$ with $70 \%$ meeting the criteria for a mental health disorder (Dierkhising, et al., 2013). This is in stark contrast to the general youth population (Silvern and Griese, 2012). Across both remand and sentenced populations, undiagnosed mental health issues following traumatic exposure are estimated to be endemic (Buckingham, 2016; Halsey, 2018). In NI, as in other regions, these details are not routinely collected or analyzed to understand associations between these traumatic experiences and violent offending.

In their study, with 658 justice-involved young people aged 13-18, Carly Dierkhising et al. (2013) found that the most frequently reported adverse events included loss and bereavement $(61.2 \%)$, domestic violence $(51.6 \%)$, physical abuse $(38.6 \%)$, and community violence $(34 \%)$.

Despite the relationship between adverse life events and violent offending (Dierkhising et al., 2013; Lansford et al., 2007; Maschi and Bradley, 2008; Smith and Thornberry, 1995; Stouthamer-Loeber et al., 2001; Topitzes et al., 2012), few studies located in NI sufficiently articulate the relationship between victimization and the perpetration of violence. This had at least in part been explained by a lack of resources dedicated to designing and collecting high quality empirical data combined with the lack of time in implementing such designs prospectively. Like in other regions, there is a need for NI to find a reliable, cost-effective, and timely approach to collecting and analyzing traumarelated violence data in order to add value to existing theory, inform policy and enhance prevention practice.

\section{Aims of this article}

$\mathrm{NI}$ is a region that continues to deal with the legacy of community violence (Lynch and Joyce, 2018) and its harms (McLafferty et al., 2015). From a public heath perspective, the violence which is understood can be prevented (Dahlberg and Krug, 2002: 3). Public health approaches for the prevention of violence have provided a framework to take decisions related to how violence is understood in a particular context, the specific risks associated with the problem in that context, what types of interventions might be appropriate and evaluative mechanisms that are required to monitor progress against agreed aims. So before intervention, the public health approach demands understanding the problem.

A report by Colm Walsh (2019) which mapped the current administrative data in NI specific to experiences of youth violence across multiple government departments found 
that data were either not collected at all or reported on in an aggregated way, thereby reducing opportunities for understanding intersections. A population-based survey found that the NI public was significantly more concerned about violent crime than those in England and Wales (NISRA, 2018). Given this, there is a legitimate and even urgent rationale to examine youth violence in the context of NI as it continues its pathway towards peace. Despite this, there is not always the time or the resources to undertake prospective studies.

In the absence of a population-based, prospective study of associations between psychological trauma and violence, there remains a need to understand predictors of violence in order to design and test approaches to prevention. The primary aim of this article is to illustrate a novel approach to data analysis using case files as the basis for retrospective analysis and outline the findings for the purpose of understanding contextually situated violent offending. This approach has potential to add value in other low-resourced areas that experience violence and has the potential to contribute to an evolving theoretical and empirical landscape for those interested in improving outcomes for both potential victims and perpetrators of violence without large scale, population-based, prospective studies.

\section{Methods}

Susanne Witte (2020) offers a useful process framework for undertaking retrospective case file analysis. This three-step process involves gathering the information (ensuring access, retrieving the case files, and considering the ethical challenges), processing the information (selecting the variables of interest, handling inconsistences), and presenting the information in a meaningful way.

Access to the case files was secured through a regional network of professionals engaged in prevention of trauma and serious youth violence. Two of these network partners involved academics from Queen's University Belfast and Senior managers from the Youth Justice Agency (YJA) of NI. Between September 2018 and this study, the network had reviewed the evidence base and formulated the following two key research questions:

1. How prevalent is childhood trauma differentiated by gender and by type?

2. Are potentially traumatic life events associated with elevated violent behavior?

This study sought to begin to address these questions by implementing a novel approach to the collection of violence-related data. Within a youth justice environment, a robust and cost-effective research design was created.

\section{Participants}

A retrospective case file review was undertaken of a 1-year cohort who had entered into the only custodial site for young people between the ages of 10 and 18 in NI. Coding involved pseudonymizing the sample using existing YJA identification. This prevented identification of individuals, while maintaining the quality assurance of the protocols 
Table I. Sample demographics.

\begin{tabular}{llc}
\hline Demographic categories & & $\%(n=134)$ \\
\hline Gender & Male & 88.7 \\
& Female & 11.3 \\
Religion & Roman catholic & 66.9 \\
& Protestant & 24.6 \\
& Other & 2.3 \\
Race & None & 6.2 \\
Age at first entry & White & 97 \\
& Irish traveller & 3 \\
& $10-12$ & 3.5 \\
& $13-15$ & 49.3 \\
\hline
\end{tabular}

within the organization. The sample arrived between January 2016 and December 2017 $(n=145)$. Organizational approval was gained from the YJA of NI to undertake the review and ethical approval was secured by the research ethics committee within Queen's University Belfast.

Of the 145 young people who engaged with the YJA of NI's Juvenile Justice Centre (JJC) in this period, a total of 134 files were reviewed. Eight files were excluded from analysis as they related to Police and Criminal Evidence (PACE) remands. These remands lasted for such short periods of time that there was insufficient data held on file and therefore no meaningful analysis could be undertaken. The last three files that were excluded from the review were related to non-national males who stayed for a period in JJC but were later determined by the Home Office to be adults and were subsequently moved. In total, $88.7 \%$ of the sample were male $(n=119)$ and the remaining $11.3 \%$ were female $(n=15)$. Sample demographics are illustrated in Table 1.

\section{Data collection}

Based on previous international work on trauma and violence, variables of interest were established prior to data collection and an electronic worksheet was developed. The worksheet consisted of the following four relevant sections.

Section 1 included demographic variables (gender, age, religion, ethnicity). The demographic data were coded dichotomously (coded as 1 or 0 ), with the exception of the age variable which was coded as a scale variable;

Section 2 included psychological variables (e.g. evidence of substance use, mental health diagnosis);

Section 3 included information related to offending history. Four variables were coded. The first captured the most serious conviction. This was coded as "summary offence," "either way," and "indictable" ordinal variables. Second, these study were 
particularly interested in interpersonal violence. If the young person had any previous conviction for a violent offence, this was coded as 1 . Conversely, the absence of a violent conviction was coded as 0 . Furthermore, if criminal histories included violent offending that was aggravated by the use of a weapon, this was coded as 1 and 0 . The number of known offences was coded as a scale variable;

Section 4 coded information about potentially traumatic experiences that had been documented. The trauma checklist was developed using a modified version of the Life Events Checklist from DSM-5 (LEC-5). Seventeen items were coded dichotomously (Weathers et al., 2013). The instrument assesses the presence of 16 adversities as well as an additional item assessing any other event not captured in the items. Two additional variables were added.

Given the unique context of NI that has been largely dominated by sectarian conflict since the 1970s, evidence for paramilitary threat and evidence of paramilitary attack were recorded. Given the evidence of dose-response effect of cumulative adversity, a final scale variable was added, representing the aggregate score of the number of unique adverse types that had been recorded for each individual. The variables of interest were presented to the network and senior management team at the YJA prior to applying for ethical approval.

Two reviewers independently reviewed each case file. Reviewer 1 was a researcher from Queen's University Belfast with a background in researching psychological trauma and youth violence. The second reviewer was a senior manager within the YJA. This combination was considered an important approach in enhancing understanding and reducing bias during the data extraction and interpretation (Tourangeau, 2000). Neither reviewer had involvement in the delivery of custodial services, reducing potential bias in the interpretation of the files (Spratt et al., 2015). The interpretation of each case file and subsequent worksheet entries were reviewed together. When disagreements appeared, the files were reviewed together, and a resolution reached. While there was provision for an additional validation step (including a third reviewer), this was not required.

Case files had originally been collected as part of routine assessment and recording. The files within which were the records were developed by professionally qualified youth justice staff and included relevant information from social services, education services, and medical services.

Variables relating to potentially traumatic events, including general exposure and specific exposure were dichotomized. In other words, the presence of an adverse life event was coded as 1 and the absence was coded as 0 .

\section{Analysis}

First, univariate analysis was performed to characterize the study population using select variables, including gender, religion, age of first entry into custody, number of those convicted of violent offences, use of weapon/s, and number of periods in custody. Descriptive statistics are reported for items collected during the review. Second, bivariate analysis with chi-square tests as well as group comparisons using independent samples $t$-tests, and 
Table 2. Trauma-related adversity.

\begin{tabular}{lrrrlc}
\hline Trauma type & \multicolumn{1}{c}{$\%$} & $N$ & Male (\%) & Female (\%) & $x^{2}$ \\
\hline Maltreatment & 36.6 & 49 & 31.4 & $84.6 * *$ & 12.13 \\
Sexual violence & 7.5 & 10 & 1.7 & $61.5 * *$ & 52.6 \\
Community violence & 31.3 & 42 & 30.6 & 38.5 & .072 \\
Paramilitary threat/violence & 29.1 & 39 & 30.6 & 15.4 & 1.31 \\
Domestic violence & 27.6 & 37 & 26.4 & 38.5 & .353 \\
Complex grief/loss & 17.2 & 23 & 17.4 & 15.4 & 0 \\
Single incident (including vehicle accident) & 2.2 & 3 & 2.5 & 0 & 0 \\
\hline
\end{tabular}

$* p<.005 ; * p<.001$.

bivariate correlations were used to examine relationships between variables. Third, multivariate logistic regression was used to explore factors increasing the predictive value of violent offending. Odds ratios were calculated with $95 \%$ confidence intervals to determine the increased odds of being convicted of a violent offence in the presence of potentially traumatic experiences after controlling for related covariates. Analyses were completed using SPSS v24.

\section{Results}

Details within the files provided evidence for exposure to trauma. The reviewers were able to use the descriptive evidence contained in the files to re-code qualitative data into quantitative measurements in order to provide a proxy measure of exposure to trauma. Of the 134 cases which provided sufficient information in order to collect trauma-related data, $61.9 \%(n=83)$ of young people had documented exposure to some form of potentially traumatic event. This ranged between 0 and $8(m=1.5)$. The specific types are outlined in the Table 2 . There was a statistically significant difference $(t=-1.83, p=.049)$ between the average number of types of potentially traumatic events experienced by young men $(m=1.4)$, and the number of those experienced by young women $(m=2.2)$, which was smaller. Although there were no statistically significant gender differences in exposure to community violence or single incident type traumas, there were significant differences elsewhere (see Table 2). Young women in the study were more likely to experience maltreatment and sexual violence, domestic violence, while young men were more likely to be exposed to paramilitary type violence.

Interestingly, $63.4 \%(n=85)$ of young people appeared to have had contact with mental health services. Of those who appeared to have been exposed to known adversities, almost one-quarter $(24.1 \%)$ had no contact with mental health services and almost onehalf $(44.6 \%)$ had no formal mental health diagnosis. The majority of those with a mental health diagnosis had Attention-Deficit Hyperactivity Disorder (ADHD), however, there was evidence of high levels of co-morbidity, particular young people with combined anxiety, PTSD and conduct disorders (see Table 4).

From the data that were available, the majority of this cohort, $81.3 \%(n=109)$, had been involved in some form of violent offending. In addition, there was evidence that within the cohort, a significant proportion $(45.6 \%, n=57)$ had been engaged in more 
Table 3. Demographics, psycho-social indicators, violent offending, and trauma experiences.

Section I: Pyscho-social indicators

Yes (\%)

Substance use

83.6

Mental health disorder

49.3

Mental health service

63.4

Section 2: Violent offending history

Violent offence

Weapons or sharps

Indictable only offences

Section 3: Potentially traumatic experiences

Any

Maltreatment

Sexual

Community violence

Domestic violence

Complex grief/loss

Paramilitary threat

Table 4. Overview of mental health disorders.

\begin{tabular}{lrr}
\hline Mental health disorder category & $N$ & $\%$ \\
\hline Anxiety & 1 & 1.5 \\
Depression & 6 & 9.1 \\
PTSD & 5 & 7.6 \\
Personality & 1 & 1.5 \\
ADHD & 30 & 45.5 \\
Conduct & 1 & 1.5 \\
Comorbid & 20 & 30.3 \\
Selective mute & 2 & 3.0 \\
Total & 66 & 100.0 \\
Missing & 68 & \\
Total & 134 & \\
\hline
\end{tabular}

ADHD: attention-deficit hyperactivity disorder; PTSD: post-traumatic stress disorder.

serious forms of violence including the use weapons or sharps, aggravating factors in their convictions.

Based on the demographic and trauma-related data collected, analyses were undertaken to establish any association between these factors and violent offending outcomes. Whether young people lived with parents or in the care of others was unrelated to either violent offending, use of weapons or offence severity. Complex grief/loss was unrelated to either violent offending, use of weapons or offence severity. Sexual violence was 
Table 5. Associations between trauma and violent offending.

\begin{tabular}{|c|c|c|c|c|}
\hline Trauma type & Category & $x^{2}$ & $d f$ & Sig. \\
\hline \multirow{3}{*}{$\begin{array}{l}\text { Potentially traumatic } \\
\text { exposure }\end{array}$} & Violent offence & 16.84 & 1 & $<.001 * * *$ \\
\hline & Weapons/sharps & 17.69 & I & $<.001 * * *$ \\
\hline & Severity & 7.50 & 3 & $.049 *$ \\
\hline \multirow[t]{3}{*}{ Maltreatment } & Violent offence & 9.35 & I & $.002^{* * * *}$ \\
\hline & Weapons/sharps & 5.9 & I & $.015^{* *}$ \\
\hline & Severity & 9.24 & 3 & $.026^{*}$ \\
\hline \multirow[t]{3}{*}{ Community violence } & Violent offence & 9.17 & I & $.002 * * *$ \\
\hline & Weapons/sharps & 22.28 & I & $<.00 I^{* * *}$ \\
\hline & Severity & 9.19 & 3 & $.027^{*}$ \\
\hline \multirow[t]{3}{*}{ Domestic violence } & Violent offence & 10.09 & I & $.00 I^{* * * *}$ \\
\hline & Weapons/sharps & 10.27 & 1 & $.001 * * *$ \\
\hline & Severity & 6.39 & 3 & .09 \\
\hline \multirow[t]{3}{*}{ Paramilitary threat/violence } & Violent offence & 1.84 & I & .11 \\
\hline & Weapons/sharps & $17.4 \mid$ & I & $<.00 I^{* *}$ \\
\hline & Severity & 8.29 & 3 & $.04 *$ \\
\hline
\end{tabular}

$* p<.05 ; * p<.005 ; * * * p<.001$.

unrelated to either violent offending, use of weapons, or offence severity. Substance use was unrelated to violent offending nor seriousness of the offence.

However, other factors did have stronger associations with violent offences, use of weapons, and offence severity. These included exposure to adverse life events generally: having been exposed to childhood maltreatment, community violence, domestic violence, and being under paramilitary threat. Table 5 illustrates the statistical significance levels from the chi-square tests.

Chi-square tests illustrated that there was a significant association between all three categories of violent offending (general violence, use of weapons/sharps, and increased severity such as indictable only offences) and exposure to trauma. However, there was also significant variation within these sub types, with maltreatment, exposure to community violence, domestic violence, and paramilitary violence more strongly associated with violent offending than other categories.

To determine if exposure to potentially traumatic events could successfully distinguish between violent and non-violent groups, a series of multivariate regressions were conducted. In the first model presented in Table 6, block entry was used to evaluate the impact of the main predictor variable (exposure to trauma) on the odds that a justiceinvolved young person would have committed a violent offence, above and beyond the effect of relevant demographic and pyscho-social covariates.

The full model contained five independent variables (age of first entry into custody, gender, a mental health diagnosis, a history of substance abuse, and general exposure to trauma). The full model containing all predictors was statistically significant, $x^{2}(5$, $n=134)=26.26, p \leqslant .001$, indicating that it was able to distinguish between those who had engaged in violent offending and those who did not. The model as a whole explained 
Table 6. Logistic regression-Model I.

\begin{tabular}{lllllll}
\hline & $B$ & SE & Wald & Sig. & OR & Cl \\
\hline Gender & -0.847 & 1.163 & 0.531 & .466 & 0.429 & $0.044-4.19$ \\
Age & 1.33 & 0.178 & 0.555 & .456 & 1.14 & $0.8 \mathrm{I}-1.62$ \\
Substance use & 0.364 & 0.602 & 0.365 & .546 & 1.44 & $0.44-4.68$ \\
Mental health diagnosis & $\mathrm{I} .5 \mathrm{I}$ & 0.57 & 6.92 & $.009 *$ & $4.5 \mathrm{I}$ & $\mathrm{I} .47-13.84$ \\
Potentially traumatic event & $\mathrm{I} .83$ & 0.58 & 9.99 & $.002 *$ & 6.22 & $2.0-19.3 \mathrm{I}$ \\
\hline
\end{tabular}

$\mathrm{Cl}$ : confidence interval; OR: odds ratio; SE: standard error. $* p=<.05$

Table 7. Logistic regression-Model 2.

\begin{tabular}{lllllll}
\hline & $B$ & SE & Wald & Sig. & OR & \multicolumn{1}{l}{ Cl } \\
\hline Maltreatment & 1.825 & 0.783 & 5.430 & .020 & 6.20 & $1.336-28.78$ \\
Community violence & 2.203 & 1.059 & 4.327 & .038 & 9.06 & $1.136-28.78$ \\
Paramilitary threat/violence & 1.798 & 1.072 & 2.814 & .093 & 6.04 & $.739-49.38$ \\
\hline
\end{tabular}

$\mathrm{Cl}$ : confidence interval; OR: odds ratio; SE: standard error.

$29.3 \%$ (Nagelkerke $R$ squared) of the variance in violent offending and correctly identified $79.7 \%$ of cases.

As shown in Table 6, two of the independent variables made a unique statistically significant contribution to the model (trauma and mental health) with the strongest variable being exposure to trauma, which recorded an odds ratio of 6.22 . This indicated that those who were exposed to some form of potentially traumatic event were more than six times more likely to be convicted of a violent offence, controlling for other variables in the model.

The first logistic regression model was statistically significant $(p \leqslant .001)$. Sensitivity analysis found that the model predicted $92.7 \%$ of violence-related convictions correctly. In fact, the addition of general exposure to trauma improved the fit of the model beyond the other variables and was a superior predictor of violent offending.

In the second model, backward conditional logistic regression was undertaken. A range of specific types of adversity (maltreatment, sexual violence, community violence, paramilitary violence, domestic violence, and complex grief) were assessed to determine if they could independently increase the predictability of engaging in violence. As several types of adversity have been demonstrated to co-occur within the youth justice population, test of multicollinearity was conducted using variance inflation factor (VIF) analysis $(1 /(1-\mathrm{R} 2))$. All but one of the items were within the acceptable VIF range of $<3$. Domestic violence was highly correlated with other independent variables in the model above the acceptable level $(>4)$ and was removed. The final model is shown in Table 7 .

In this model, the best fit included three specific forms of adversity. Two of the variables made a unique statistically significant contribution to the model (maltreatment and exposure to community violence) with the strongest variable being exposure to community violence, which recorded an odds ratio of 9.06. This indicated that those who were 
Table 8. Logistic regression-Model 3.

\begin{tabular}{lrlllll}
\hline & \multicolumn{1}{l}{$B$} & SE & Wald & Sig. & OR & Cl \\
\hline Maltreatment & 0.691 & 0.483 & 2.049 & .152 & 1.996 & $0.775-5.14$ \\
Sexual abuse & -0.883 & 0.859 & 1.058 & .304 & 0.413 & $0.077-2.23$ \\
Community violence & 1.296 & 0.594 & 4.756 & .029 & 3.656 & $1.140-11.72$ \\
Paramilitary threat/violence & 0.944 & 0.577 & 2.676 & .102 & 2.569 & $0.829-7.96$ \\
Complex grief & 1.047 & 0.559 & 3.500 & .061 & 2.848 & $0.951-8.53$ \\
Mental health diagnosis & 0.505 & 0.423 & 1.423 & .233 & 1.656 & $0.723-3.80$ \\
\hline
\end{tabular}

$\mathrm{Cl}$ : confidence interval; OR: odds ratio; SE: standard error.

exposed to community violence were more than nine times more likely to be convicted of a violent offence, controlling for other variables in the model.

In addition to violent convictions, analysis was undertaken to explore the association between the range of variables and engagement in violent crimes where weapons and/or sharps had been used. In the third model shown in Table 8, a range of specific types of adversity were assessed to determine if they could independently increase the predictability of engaging in more serious forms of violence where weapons or sharps were used, controlling for mental health issues. The full model contained six independent variables (maltreatment, sexual violence, community violence, paramilitary violence, complex grief, and a mental health diagnosis). The full model containing all predictors was statistically significant, $x^{2}(6, n=134)=36.42, p \leqslant .001$, indicating that it was able to distinguish between those who had engaged in violent offending and those who did not. The model as a whole explained 33.8\% (Nagelkerke $R$ squared) of the variance in weapons use. Sensitivity analysis found that although the null model predicted $0 \%$ correctly, the full regression correctly predicted $58 \%$ of violence-related convictions where weapons were used.

This regression model was statistically significant and increased the overall predictability from $54.4 \%$ to $70.4 \%$, representing a $16 \%$ increase between the null and final model. In line with Model 2, exposure to community violence remained a stable predictor. In fact, it was the strongest predictor of weapon use and the only independent variable that was statistically significant. Interestingly, complex grief become marginally significant and although exposure to paramilitary threat/violence was not statistically significant, those who were exposed to this form of trauma were more than two and a half times more likely to be convicted of a violent offence, aggravated by the use of weapons. That is, those who experienced paramilitary victimization were at increased risk of perpetrating more serious forms of violence themselves compared to those who had not experienced paramilitary victimization.

In line with theories such as the general strain theory, some forms of trauma appeared to be more strongly related to violent offending than others.

\section{Discussion}

As far as the authors are aware, this is the first study that has examined the impact of childhood adversity on violence-related outcomes among a justice-involved sample of 
young people in NI. Given the legacy of conflict and evidence of pervasive violence within some communities, there is a need to understand the needs of those engaged in and victims of violence within this context. Given the challenges associated with collecting high quality, population-based data prospectively, the approach detailed here illustrates that where this is not possible, routinely collected data-reanalyzed for a different purpose can provide novel insights. There are, of course, limitations with this approach. As with other secondary studies, an inherent problem is that these data have not been collected to specifically address the particular research question or to test the current hypothesis. This was partially offset during this process in which the data available were examined prior to the development of the data collection template. In this way, the researchers understood what was, and what was not available. The questions were, therefore, developed within the parameters of the case file data. A further limitation is that the files contain subjective records of events as opposed to an assessment of an individual's distress following those events. While direct engagement with young people is often preferable, where this is not feasible (e.g. due to costs or time) then the process outlined in this article is a reasonable option. This study contributes to the empirical evidence base, given the paucity of intersectional data between psychological distress and interpersonal violence (Walsh, 2019), provides some evidence for new and novel approaches to prevention and can provide leverage to potential commissioners to invest in prospective data collection.

It has been established in previous studies that a strong association exists between exposure to adversity during childhood and violent behavior (Fox et al., 2015; Piquero, 2011). Despite the association, youth justice systems do not routinely or consistently screen for such issues. Using this novel case file approach, this study documented known exposure to different adversities and evaluated the potential impact that these childhood adversities could and can have on violent offending within this population, controlling for other known influential factors. The results from the univariate analysis demonstrate that young people within this study have experienced a range of adverse life events as well as a history of known violent offending in line with previous studies (Baglivio et al., 2021; Maxfield and Widom, 1996).

In an attempt to understand the associations between exposure to trauma and violent behaviour bivariate analyses were undertaken. While trauma generally was associated with increased levels of violence, some forms of adversity were more strongly associated with violence than others. These included maltreatment (Maxfield and Widom, 1996), domestic violence and community violence with the latter being a stable predictor across tests. While confirming the impact of adversity on behaviour, the findings also support the argument that violence begets violence is not always the case (Stouthamer-Loeber et al., 2001), as specific forms of adversity are more strongly associated with violent outcomes than others.

Multivariate analysis illustrated that it was possible to distinguish between violent and non-violent youth within the cohort. Across the three regression models, exposure to community violence was a stable predictor of violent offending in each case, increasing the odds significantly. These findings complement those from previous studies (e.g. Milaniak and Widom, 2015) that have suggested that broad measures against adversity, specifically those limited to the family environment, reduce the understanding of causal 
factors that contribute to violent offending and the socio-emotional pathways that link trauma to violence (Walsh, 2020b). Similar associations have been found in previous studies (e.g. Farrell and Zimmerman, 2017), albeit the odds were even higher in this population. This could be a reflection of the design or may indicate latent adversities that were unrecorded by professionals, and therefore, not accounted for in the analysis.

While much of the data align closely with other investigations internationally, some of the findings were contextually related to NI. In particular, young people in this study were exposed to organized crime such as paramilitary threats and/or assaults. While this did not uniquely predict violent offending, those who were exposed to it were at increased odds of engaging in violent offending and further, those exposed to this form of violent abuse were significantly more likely to engage in more serious forms of violence where weapons/sharps were used and where the offences were classified as "indictable," compared to other young people who were not known to have experienced paramilitary harms.

As noted earlier, despite the benefits, there are limitations with this case file review approach, including a reliance on subjective recordings of professionals. A further limitation is the limited capacity to assess the temporal sequence of predictors and outcomes. For instance, it may be the case that violent behaviour increases the odds of an individual to become the victim rather than the victim becoming more likely to perpetrate violence. While subsequent studies may help to establish the causal pathways more coherently, this study does support the theoretical approach that suggest that an increased exposure to particular forms of adversity place strains on individuals who, with limited resources, resort to behaviour that is maladaptive, potentially dangerous and deemed criminal.

In line with Agnew's (2001) update on the general strain theory that posits the importance of specific strains on individuals, this study illustrates that some forms of adversity increase the odds of perpetrating violence more than others. Theories such as Agnew's strain suggest that in the face of adversity, traumatic responses (both in terms of severity and/or cumulative impact) may involve maladapted behaviors, including heightened aggressive responses, particularly for those who have limited (perceived or actual) alternative resources (Anderson, 1999). However, as these findings also illustrate, while necessary, strains alone appear to be insufficient to fully explain the perpetration of violence and alternative or indeed complementary theories could help advance our understanding. For example, it has been speculated that the significant gender variations in violent offence is mediated by socially constructed, subjective gender norms (Blum et al., 2019; Nygaard et al., 2018; Topitzes et al., 2012; Zahn-Waxler et al., 2008). This study was unable to test for this; nevertheless, it was clear that the majority of this cohort was male and a significant proportion had histories of violent offending. But due to the low numbers of females, regression models were not powered to make meaningful gender comparisons. Future studies should examine the effect of traditional gender norms that victims hold, the subjective meanings associated with adversity and the effect this may have on behavioral responses following traumatic exposure.

In addition, despite previous studies illustrating that it is not merely the presence of a particular form of trauma which is significant, but the meanings attached to those adversities (McGee et al., 1997), few studies have examined subjective strains disaggregated by gender and the socially constructed meanings that are attached to adversity. In addition to the collection and analysis of data in standardized form, combining methods to 
include qualitative elements could provide context. By understanding the meanings attached to adversity, the mechanisms that link trauma to violence may become clearer.

\section{Conclusions and future directions}

Violence is a pervasive and complex social issue. Understanding its prevalence and who is most at risk of both victimization and perpetration could enhance prevention efforts. Despite widespread acceptance that adversity is predictive of such deleterious outcomes, few studies have examined the association in the context of NI, which continues to transition from conflict to peace. Furthermore, there appears to be a need to understand youth violence in a more nuanced way. Without appropriate data, this becomes more difficult, potentially affecting prevention efforts. This study illustrated the potential contribution of re-analyzing routinely collected data to at least partially address this data gap.

It is true that most of those who experienced childhood adversity do not go on to engage in violent offending (Topitzes et al., 2012). However, this study found that rates of both adversity and violent offending were high and strongly associated within this population. This research adds to this growing body of evidence that within the broad theme of adversity, there are significant nuances, providing a baseline for future investigation. This study suggests that there is a relationship between exposure to extra-familial, community violence, and violent offending. Of particular note in the context of NI is the prevalence of paramilitary threat among this cohort and the increased odds of serious violent offending.

The approach applied in this study is important in that it provided an evidential basis for future work in the absence of high-quality disaggregated data. Future work should build on this prospectively to understand the mechanisms that underlie linkages between these forms of adversity and subsequent offending (Lansford et al., 2007). Prospective studies would allow examination of the temporal sequence of event and allow for the control of further covariates such as deprivation.

\section{Declaration of Conflicting Interests}

The authors declared no potential conflicts of interest with respect to the research, authorship, and/ or publication of this article.

\section{Funding}

The authors received no financial support for the research, authorship, and/or publication of this article.

\section{ORCID iD}

Colm Walsh (iD https://orcid.org/0000-0003-2834-2865

\section{References}

Abate A, Marshall K, Sharp C, et al. (2017) Trauma and aggression: Investigating the mediating role of mentalizing in female and male inpatient adolescents. Child Psychiatry and Human Development 48: 881-890. 
Agnew R (1992) Foundation for a general strain theory of crime and delinquency. Criminology 30(1): 47-88.

Agnew R (2001) Building on the foundation of general strain theory: Specifying the types of strain most likely to lead to crime and delinquency. Journal of Research in Crime and Delinquency 38: 319-361.

Anderson E (1999) Code of the Street. New York: Norton.

Baglivio M, Wolff K and Epps N (2021) Violent juveniles' adverse childhood experiences: Differentiating victim groups. Journal of Criminal Justice 72: 101769.

Bandura A (1979) Social Learning Theory. Englewood Cliffs, NJ: Prentice Hall.

Bellis M, Hughes K, Leckenby N, et al. (2014) National household survey of adverse childhood experience and their relationship with resilience to health-harming behaviours in England. BMC Medicine 12: 72.

Blum R, Li M and Naranjo-Rivera G (2019) Measuring adverse child experiences among young adolescents globally: Relationships with depressive symptoms and violence. Journal of Adolescent Health 65(1): 86-93.

Breslau N, Davis GC, Andreski P, et al. (1991) Traumatic events and posttraumatic stress disorder in an urban population of young adults. Archives of General Psychiatry 48: 216-222.

Breslau N, Davis GC, Andreski P, et al. (1997) Sex differences in posttraumatic stress disorder. Archives of General Psychiatry 54: 1044-1048.

Brewin CR, Andrews B and Valentine JD (2000) Meta-analysis of risk factors for post-traumatic stress disorder in trauma-exposed adults. Journal of Consulting and Clinical Psychology 68: $748-766$.

Buckingham S (2016) Trauma informed juvenile justice. American Crime Law Review 53: 641-692.

Bunting L, McCartan C, Davidson G, et al. (2020) The Mental Health of Children and Parents in Northern Ireland: Results of the Youth Wellbeing Prevalence Survey. Belfast: Health and Social Care Board.

Dahlberg L and Krug E (2002) Violence: A global public health problem. In: Krug E, Dahlberg J, Mercy A, et al. (eds) World Report on Violence and Health. Geneva: World Health Organization, pp. 1-21.

Dierkhising C, Ko S, Woods-Jaeger B, et al. (2013) Trauma histories among justice-involved youth: Findings from the National Child Traumatic Stress Network. European Journal of Psychotraumatology 4(1): 20274.

EANI (2020) From Scoping to Supporting: A Meta-Evaluation of Targeted Youth Delivery Projects. Belfast: Education Authority for Northern Ireland.

Fargas-Malet M and Dillenburger K (2016) Intergenerational transmission of conflict-related trauma in Northern Ireland: A behavior analytic approach. Journal of Aggression, Maltreatment \& Trauma 25(4): 436-454.

Farrell C and Zimmerman G (2017) Does offending intensify as exposure to violence aggregates? Reconsidering the effects of repeat victimization, types of exposure to violence, and polyvictimization on property crime, violent offending, and substance use. Journal of Criminal Justice 53: 25-33.

Fay M, Morrissey M and Smyth M (1998) Mapping Troubles-Related Deaths in Northern Ireland 1969-1998, 2nd edn. Derry; Londonderry: INCORE.

Felitti VJ, Anda RF, Nordenberg D, et al. (1998) Relationship of childhood abuse and household dysfunction to many of the leading causes of death in adults. The Adverse Childhood Experiences (ACE) Study. American Journal of Preventive Medicine 14(4): 245-258.

Ferry F, Bunting B, Murphy S, et al. (2014) Traumatic events and their relative PTSD burden in Northern Ireland: A consideration of the impact of the "Troubles". Social Psychiatry and Psychiatric Epidemiology 49(3): 435-446. 
Fonagy P (1999) The transgenerational transmission of holocaust trauma. Attachment \& Human Development 1: 92-114.

Fox B, Perez N, Cass E, et al. (2015) Trauma changes everything: Examining the relationship between adverse childhood experiences and serious, violent and chronic juvenile offenders. Child Abuse \& Neglect 36: 163-173.

Goodman RD and West-Olatunji CA (2008) Trans-generational trauma and resilience: Improving mental health counselling for survivors of Hurricane Katrina. Journal of Mental Health Nursing 30: 121-136.

Halsey M (2018) Child victims as adult offenders: Foregrounding the criminogenic effects of (unresolved) trauma and loss. British Journal of Criminology 57: 17-36.

Henggeler SW, Schoenwald SK, Borduin CM, et al. (1998) Multisystemic Treatment of Antisocial Behavior in Children and Adolescents. New York: Guildford Press.

Jennings WG, Piquero AR and Reingle JM (2012) On the overlap between victimization and offending: A review of the literature. Aggression and Violent Behavior 17: 16-26.

Kapur R and Campbell J (2004) The Troubled Mind of Northern Ireland. London: Karnac Books.

Kar H (2019) Acknowledging the victim to perpetrator trajectory: Integrating a mental health focused trauma-based approach into global violence programs. Aggression and Violent Behavior 47: 293-297.

Kellermann NP (2001) Transmission of Holocaust trauma: An integrative view. Psychiatry: Interpersonal and Biological Processes 64: 256-267.

Kessler RC, Sonnega A, Bromet E, et al. (1995) Posttraumatic stress disorder in the National Comorbidity Study. Archives of General Psychiatry 52(12): 1048-1060.

Knox C (2002) See no evil, hear no evil: Insidious paramilitary violence in Northern Ireland. The British Journal of Criminology 42(1): 164-185.

Lansford J, Miller-Johnson S, Berlin L, et al. (2007) Early physical abuse and later violent delinquency: A prospective longitudinal study. Child Maltreatment 12(2): 233-245.

Levenon J and Grady M (2016) Childhood adversity, substance abuse and violence: Implications for trauma informed practice. Journal of Social Work Practice in the Addictions 16(1): 24-45.

Lynch O and Joyce C (2018) Functions of collective victimhood: Political violence and the case of the Troubles in Northern Ireland. International Review of Victimology 24(2): 183-197.

McAlister S, Scraton P and Haydon D (2011) Place, territoriality and young people's identity in the "new" Northern Ireland. In: Goldson B (ed.) Youth in Crisis? "Gangs," Territoriality and Violence. London: Routledge, pp. 89-109.

McGee R, Wolfe D and Wilson S (1997) Multiple maltreatment experiences and adolescent behavior problems: Adolescents' perspective. Development and Psychopathology 9: 131-149.

McGuigan K and Shevlin M (2010) Longitudinal changes in posttraumatic stress in relation to political violence (Bloody Sunday). Traumatology 1: 1-6.

McKittrick D, Kelters S and Feeney B (2007) Lost Lives: The Stories of the Men, Women and Children Who Died as a Result of the Northern Ireland Troubles. Edinburgh: Mainstream Publishing Company.

McLafferty M, Armour C, McKenna A, et al. (2015) Childhood adversity profiles and adult psychopathology in a representative Northern Ireland study. Journal of Anxiety Disorders 35: $42-48$.

Maschi T and Bradley C (2008) Exploring the moderating influence of delinquent peers on the link between trauma, anger, and violence among male youth: Implications for social work practice. Journal of Child and Adolescent Social Work 25: 125-138.

Maxfield MG and Widom CS (1996) The cycle of violence: Revisited six years later. Archives of Pediatric and Adolescent Medicine 150: 390-395. 
Milaniak I and Widom C (2015) Does child abuse and neglect increase risk for perpetration of violence inside and outside the home? Psychology of Violence 5(3): 246-255.

NISRA (2018) Experience of Crime: Findings from the 2017/18 Northern Ireland Crime Survey. Belfast: Northern Ireland Statistics and Research Agency.

Nygaard R, Marek A, Daly S, et al. (2018) Violent trauma recidivism: Does all violence escalate. European Journal of Trauma and Emergency Surgery 44: 851-858.

Piquero AR (2011) James Joyce, Alice in Wonderland, the Rolling Stones, and criminal careers. Journal of Youth and Adolescence 40: 761-775.

Prinsloo M, Bradshaw D and Neethling I (2015) The consequences of violence: Assessing the health burden of violence. In: Donnelly P and Ward C (eds) Oxford Textbook of Violence Prevention: Epidemiology, Evidence and Policy: An Evidence-Based Guide. Oxford: Oxford University Press, pp. 89-103.

Schwerdtfeger KL, Larzelere RE, Werner D, et al. (2013) Intergenerational transmission of trauma: The mediating role of parenting styles on toddlers' DSM-related symptoms. Journal of Aggression, Maltreatment \& Trauma 22: 211-229.

Shaffer C, Douglas K, Fuller E, et al. (2019) Do community structural characteristics moderate the association between mental health and the frequency and severity of violent-behavioral outcomes in community respondents? Journal of Interpersonal Violence. Epub ahead of print 2 December. DOI: 10.1177/0886260519888204.

Silvern L and Griese B (2012) PTSD, depression, dissociation and recidivism among delinquent youth. Journal of Child and Adolescent Trauma 5: 88-101.

Smith C and Thornberry TP (1995) The relationship between childhood maltreatment and adolescent involvement in delinquency. Criminology 33: 451-481.

Smyth M, Fay M, Emily E, et al. (2004) The Impact of Political Conflict on Children in Northern Ireland. Belfast: Institute of Conflict Research.

Spratt T, Devaney J and Hayes D (2015) In and out of home care decisions: The influence of confirmation bias in developing decision supportive reasoning. Child Abuse \& Neglect 49: 76-85.

Stouthamer-Loeber SM, Loeber R, Homish E, et al. (2001) Maltreatment of boys and the development of disruptive and delinquent behaviour. Development and Psychopathology 13(4): 941-955.

Topitzes J, Mersky J and Reynolds A (2012) From child maltreatment to violent offending: An examination of mixed gender and gender specific models. Journal of Interpersonal Violence 27(12): 2322-2347.

Tourangeau R (2000) Remembering what happened: Memory errors and survey reports. In: Stone AA (ed.) The Science of Self-Report: Implications for Research and Practice. Mahwah, NJ: Lawrence Erlbaum.

Van der Kolk BA, McFarlane AC and Weisaeth L (eds) (1996) Traumatic Stress: The Effects of Overwhelming Experience on Mind, Body, and Society. New York: Guilford Press.

Volkan VD (1996) Bosnia-Herzegovina: Ancient fuel for a modern inferno. Mind and Human Interaction 7(3): 110-127.

Walsh C (2019) Pathways and Outcomes: A Review of What Administrative Data in NI Can Tell Us about the Prevalence and Prevention of Paramilitary and Serious Youth Violence. Belfast: Department of Justice.

Walsh C (2020a) The 3 P's: Personal safety, policing and paramilitaries. ARK 135. Available at: https://www.ark.ac.uk/ARK/sites/default/files/2020-11/update135.pdf

Walsh C (2020b) The utility of a psycho-social approach for understanding and addressing male youth violence: The interface between traumatic experiences and masculinity. Journal of Aggression, Maltreatment \& Trauma 29(2): 186-205. 
Walsh C and Schubotz D (2020) Young men's experiences of violence and crime in a society emerging from conflict. Journal of Youth Studies 23(5): 650-666.

Weathers FW, Blake DD, Schnurr PP, et al. (2013) The life events checklist for DSM-5 (LEC-5). National Center for PTSD. Available at: https://www.ptsd.va.gov

WHO (2020) Global Status Report on Preventing Violence against Children 2020. Geneva: World Health Organization.

Widom CS (1989) Child abuse, neglect and adult behavior: Research design and findings on criminality, violence, and child abuse. American Journal of Orthopsychiatry 59: 355-367.

Witte S (2020) Case file analyses in child protection research: Review of methodological challenges and development of a framework. Children and Youth Services Review 108: 104551.

Wright K, Turnovic J, O'Neal E, et al. (2019) The cycle of violence revisited: Childhood victimisation, resilience and future violence. Journal of Interpersonal Violence 34(6): 1261-1286.

YANI (2001) Everyday Life. Belfast: YouthAction Northern Ireland.

Yehuda R, Engel SM, Brand SR, et al. (2005) Transgenerational effects of posttraumatic stress disorder in babies of mothers exposed to the World Trade Center attacks during pregnancy. The Journal of Clinical Endocrinology \& Metabolism 90: 4115-4118.

Zahn-Waxler C, Park J, Usher C, et al. (2008) Young children's representations of conflict and distress: A longitudinal study of boys and girls with disruptive behavior problems. Development and Psychopathology 20: 99-119.

\section{Author biographies}

Colm Walsh is Senior Fellow at Queen's University Belfast and chair of the regional youth violence and psychological trauma network in Northern Ireland. Colm's main research interests are related to understanding and preventing serious youth violence through data-driven planning and evidence-informed delivery.

Kelvin Doherty is assistant director with the Youth Justice Agency in Northern Ireland. Kelvin is involved in the strategic prevention of youth offending and is particularly interested in evidencebased and children's rights-based approaches to delivery.

Paul Best is lecturer in Social Work at Queen's University Belfast and director of the Digital Mental Health Network. Paul's main research interests relate to psychological trauma, the application of evidence-based practices such as cognitive behavioral therapy and the use of novel innovations to improve outcomes. 